\title{
Morphological and Morphometric Analysis of the External Aperture of the Carotid Canal in Serbian Population
}

\author{
Análisis Morfológico y Morfométrico de la Apertura Externa \\ del Canal Carotídeo en la Población Serbia
}

Nikolina Pupovac ${ }^{1}$; Mirela Eric'; Slobodan Sekulic ${ }^{2}$; Nikola Knezi ${ }^{1}$; Angelina Vlaski ${ }^{3}$; Dragica Hajder ${ }^{2} \&$ Branka Petkovic $^{4}$

\begin{abstract}
PUPOVAC, N.; ERIC, M.; SEKULIC, S.; KNEZI, N.; VLASKI, A.; HAJDER, D. \& PETKOVIC, B. Morphological and morphometric analysis of the external aperture of the carotid canal in Serbian population. Int. J. Morphol., 38(4):1026-1031, 2020.

SUMMARY: The carotid canal is located in the petrous part of the temporal bone and transmits the internal carotid artery along with the venous and sympathetic nerve plexus. The shape, location and dimensions of the carotid canal are clinically very important especially in cases of skull base surgery. The aim of this study was to investigate the morphological and morphometric parameters of the external aperture of the carotid canal in Serbian population. The study included 24 dry adult skulls and 36 dry adult temporal bones. Diameters and distances of the external aperture of the carotid canal from various important landmarks of the skull base were measured. The shape of the external carotid canal aperture was also noted. Digital data were processed in the ImageJ software. The average length of the external aperture of the carotid canal in all investigated specimens (skulls and temporal bones) on the right and left sides was $7.31 \pm 1.01 \mathrm{~mm}$ and $7.71 \pm 1.06 \mathrm{~mm}$, respectively. The average width of the external aperture of the carotid canal on the right side was $5.82 \pm 0.78 \mathrm{~mm}$ while on the left side was $6.20 \pm 1.04 \mathrm{~mm}$. The frequency of different shapes of the external aperture of the carotid canal was as follows: round in 45 (53.57 \%), oval in 25 (29.76 \%), and the rarest was almond shape noted in $13(15.47 \%)$ cases. There were no statistically significant differences in all measured parameters between genders and body sides. The only statistical significance was found in females between right and left side in relation with length (AP diameter) of the external aperture of the carotid canal. The results of this study will be useful for neurosurgeons to improve different surgical approaches to the petrous part of the internal carotid artery and prevent its complications.
\end{abstract}

KEY WORDS: Carotid canal; Morphology; Morphometry; Skull; Temporal bone.

\section{INTRODUCTION}

The carotid canal is a bony canal that begins with the external aperture (EACC) located on the lower surface of the petrous part of the temporal bone, in front of the jugular fossa (Berkoviz \& Moxham, 1988; Standring, 2016). Beginning from the EACC, the carotid canal, runs upward for a distance of $1 \mathrm{~cm}$ and then bends on itself at almost a right angle (Somesh et al., 2014), leading horizontally forward and toward the medial side, to the apex of the petrous part of the temporal bone by about 2 to $3 \mathrm{~cm}$, and then ending, forming the internal aperture of the carotid canal (IACC). This opening is located in front of the foramen lacerum, intracranially. The carotid canal transmits the large vessel, internal carotid artery (ICA) along with a venous plexus and sympathetic nerve plexus (Standring; Naidoo et al., 2017). Although skull base anatomy is considered to be a major determinant of gender in forensic medicine, the role of skull base openings as neurovascular routes is especially important in the surgical environment (Berlis et al., 1992; Cicekcibasi et al., 2004; Chimmalgi et al., 2007). Internal carotid artery injuries occur in $1 \%$ of individuals who experience severe head trauma. Complications for carotid injuries may include stroke, pseudoaneurysm formation and death (York et al., 2005). Resnick et al. (1997) found that the risk of carotid artery injury was significantly higher in patients with the carotid canal fracture than in patients with skull base fractures, who did not have a carotid canal fracture. The carotid canal was chosen as the landmark because of its importance and easy identification on magnetic resonance tomography (MRT) angiography and digital subtraction angiography (DSA) (Tewari et al., 2018). A thorough knowledge of the

\footnotetext{
${ }^{1}$ Department of Anatomy, Faculty of Medicine, University of Novi Sad, Serbia.

${ }^{2}$ Department of Neurology, Faculty of Medicine, University of Novi Sad, Neurology Clinic, Clinical Center of Vojvodina, Serbia.

${ }^{3}$ Faculty of Medicine, University of Novi Sad, Serbia.

${ }^{4}$ Department of Neurophysiology, Institute for Biological Research "Sinisa Stankovic" - National Institute of Republic of Serbia, University of Belgrade, Serbia.
} 
normal and variant position of the carotid canal is important for neuroradiologists and neurosurgeons in cases of aneurysm and clivus microsurgery, as well as in order to improve different surgical approaches to the internal carotid artery in the petrous part of the temporal bone. The aim of this study was to determine the morphometric parameters and shape of the EACC in Serbian population and to correlate it with sex and body side.

\section{MATERIAL AND METHOD}

The study included 84 temporal bones ( 24 dry adult human skulls and 36 dry human temporal bones) which belong to the collection of the Department of Anatomy, Faculty of Medicine, University of Novi Sad. Only those bones and skulls with preserved bony structures and openings at their inferior surface were considered. The sample consisted of 12 male skulls, 12 female skulls, 16 right temporal bones and 20 left temporal bones. The sex of the skull was determined based on the assessment of the next four morphological structures: external occipital protuberance, mastoid process, supraorbital margin, and glabella (Stevenson et al., 2009). The skulls were placed in a horizontal position with the base facing up and that surface was photographed. Similarly, after orientation the temporal bones were placed in a horizontal position so that the underside of the petrous part of the temporal bone was facing upward while we photographed it. We used an Olympus sp-560uz digital camera with $18 \mathrm{x}$ optical zoom. The following parameters were measured (Fig. 1): 1. anteroposterior (AP) diameter of the EACC; 2 . transverse (ML) diameter of the EACC (these two parameters were measured in all included specimens); 3 . Shortest distance from the midline of the base of the skull (Mid) to the CC; 4 . Shortest distance from foramen magnum (FM) to the CC; 5 . Shortest distance from the tip of the mastoid process (MP) to the $\mathrm{CC}$ (these three parameters were measured on the skulls). On the six male skulls we were not able to measure the parameter of the shortest distance from foramen magnum (FM) to the EACC because of bone damage in this area.

The shape of the EACC was also noted. All images transferred to the computer and we measured following parameters on both sides using a computer program Image $\mathrm{J}$ $1.48 \mathrm{v}$. All of the measurements were taken three times by the same person, and the mean value, expressed in millimeters, was taken as the reference.

Statistical Analysis. The results are presented as parameters of descriptive statistics (mean), standard deviation (SD), minimum and maximum (Min-Max)). A Student's t-test was used to determine the difference between sexes and sides, while one-way ANOVA test was used to compare the mean values of EACC length and width for different types of shape. A statistically significant difference was considered if $\mathrm{p}<$ 0.05 .

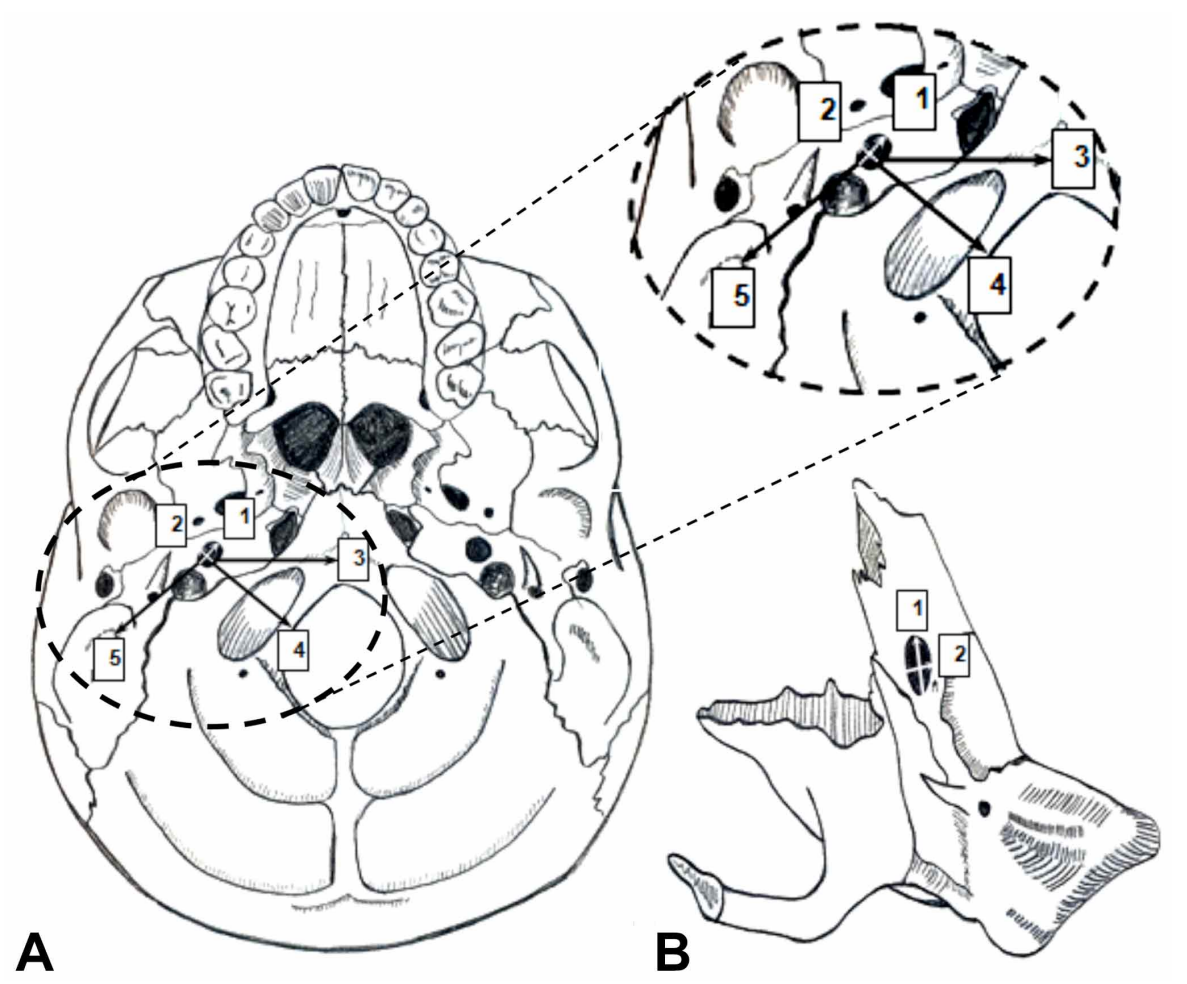

Fig. 1. Measured parameters of the skull (A): anteroposterior diameter of the EACC (1); transverse diameter of the EACC (2); the shortest distance from the midline of the base of the skull to the CC (3); the shortest distance from foramen magnum to the CC (4); the shortest distance from the tip of the mastoid process to the $\mathrm{CC}$ (5). Measured parameters of the temporal bone (B): anteroposterior diameter of the EACC (1); transverse diameter of the EACC (2). 


\section{RESULTS}

The mean values of the EACC length and width of all measured specimens (skulls and temporal bones) are shown in Table I. There were no statistically significant differences of the length and width of the EACC between sides.

After dividing the examined skull specimens by the gender, there was statistically significant difference in female skulls between right and left length (AP diameter) values of EACC $(p=0.017)$. Significantly higher values were noted on the right side. In the other skull-based parameters, there were no statistically significant differences between genders and sides. The mean values of these parameters are shown in Table II.
In $45(53.57 \%)$ cases we found the round shape of EACC, oval in $25(29.76 \%$ ), and the rarest shape was almond found in $13(15.47 \%)$ cases. On the temporal bones, the most common shape was round on the right and left sides in $9(56.25$ $\%)$ and in $11(55 \%)$ cases, oval shape on the right and left sides in $7(43.75 \%)$ and in $4(20 \%)$ cases, almond shape on the right side was absent and on the left side was present in 5 $(25 \%)$ cases. The varios shapes of the EACC are shown in Table III and Figure 2.

In male skulls, the most common shape of the EACC on the right and left sides was round noted in $7(55.33 \%)$ cases. In female skulls, the most common shape of the EACC on the right side was round noted in $5(41.66 \%$ ) while on the left side frequency of the round and oval shape was equal - 6 $(50 \%)$ cases. The almond shape was the rarest in both sexes.

Table I. The results of measurements of the average length and width of the EACC on the all skulls and temporal bones.

\begin{tabular}{lccccrr}
\hline EACC & \multicolumn{2}{c}{ Right side } & \multicolumn{2}{c}{ Left side } & $t$ & $p$ \\
& $\mathrm{X} \pm \mathrm{SD}$ & Min-M_x & $\mathrm{X} \pm \mathrm{SD}$ & Min-M-x & & \\
\hline Lenght (AP) $\mathrm{mm}$ & $7.31 \pm 1.01$ & $4.75-9.91$ & $7.71 \pm 1.06$ & $5.68-10.33$ & 1.76 & 0.08 \\
Widht (ML) mm & $5.82 \pm 0.78$ & $4.42-7.98$ & $6.20 \pm 1.04$ & $4.38-10.89$ & 1.89 & 0.06 \\
\hline
\end{tabular}

Table II. Differences between right and left sides of skull bases in relation to the sex.

\begin{tabular}{|c|c|c|c|c|c|c|c|c|}
\hline & & & & & & & & \\
\hline & $\begin{array}{c}\text { Right side } \\
\mathrm{X} \pm \mathrm{SD}\end{array}$ & $\begin{array}{c}\text { Left side } \\
\mathrm{X} \pm \mathrm{SD}\end{array}$ & $t$ & $p$ & $\begin{array}{c}\text { Right side } \\
\mathrm{X} \pm \mathrm{SD}\end{array}$ & $\begin{array}{c}\text { Left side } \\
\mathrm{X} \pm \mathrm{SD}\end{array}$ & $t$ & $p$ \\
\hline AP & $7.49 \pm 1.19$ & $7.77 \pm 1.13$ & 0.60 & 0.55 & $7.18 \pm 0.42$ & $7.96 \pm 0.96$ & 2.58 & 0.017 \\
\hline ML & $5.69 \pm 0.78$ & $6.41 \pm 1.61$ & 1.39 & 0.17 & $5.75 \pm 0.36$ & $5.96 \pm 0.92$ & 0.75 & 0.46 \\
\hline EACC-MS & $25.06 \pm 2.35$ & $26.36 \pm 3.95$ & 0.97 & 0.34 & $25.63 \pm 3.15$ & $25.12 \pm 3.10$ & 0.39 & 0.69 \\
\hline EACC-FM & $19.36 \pm 2.43$ & $21.36 \pm 3.22$ & 1.48 & 0.15 & $20.41 \pm 4.36$ & $19.90 \pm 3.21$ & 0.32 & 0.75 \\
\hline EACC-MP & $29.81 \pm 2.72$ & $30.26 \pm 1.67$ & 0.48 & 0.63 & $27.66 \pm 3.32$ & $29.18 \pm 1.65$ & 1.41 & 0.17 \\
\hline
\end{tabular}
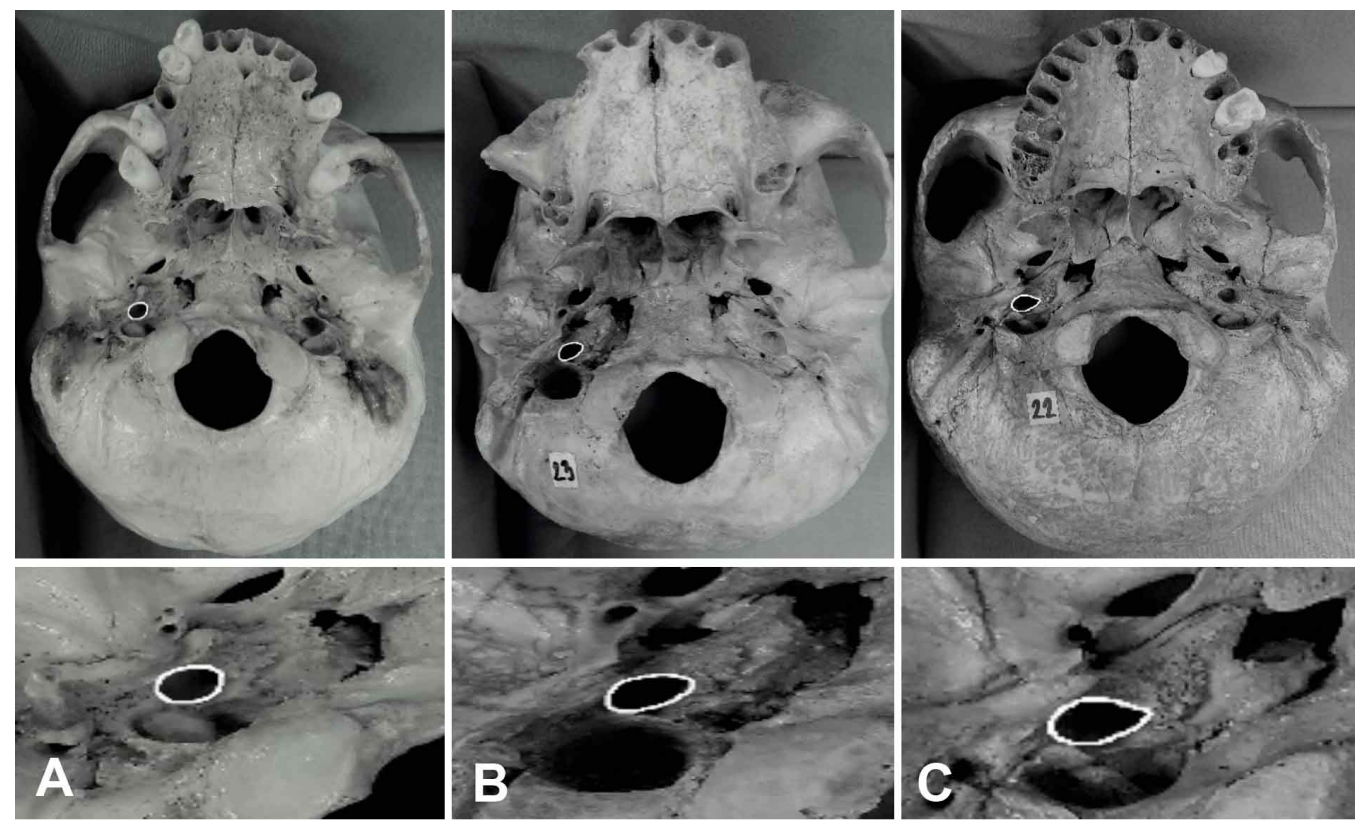

Fig. 2. Shapes of the EACC: round-shaped (A), oval-shaped (B), almond-shaped (C). 
Table III. Various shapes of the EACC.

\begin{tabular}{|c|c|c|c|c|c|c|c|}
\hline \multirow{3}{*}{ Shape } & \multicolumn{4}{|c|}{ Skulls $(n=24)$} & \multirow{2}{*}{\multicolumn{2}{|c|}{ Temporal bones $(n=36)$}} & \multirow{3}{*}{ Total $(n=84)$} \\
\hline & \multicolumn{2}{|c|}{ Male $(n=12)$} & \multicolumn{2}{|c|}{ Female $(n=12)$} & & & \\
\hline & Right & Left & Right & Left & Right $(n=16)$ & Left $(n=20)$ & \\
\hline Round & $7(55.33 \%)$ & $7(55.33 \%)$ & $5(41.66 \%)$ & $6(50 \%)$ & $9(56.25 \%)$ & $11(55 \%)$ & $45(53.57 \%)$ \\
\hline Oval & $2(16.66 \%)$ & $3(25 \%)$ & $3(25 \%)$ & $6(50 \%)$ & $7(43.75 \%)$ & $4(20 \%)$ & $25(29.76 \%)$ \\
\hline Almond & $3(25 \%)$ & $2(16.66 \%)$ & $3(25 \%)$ & 0 & 0 & $5(25 \%)$ & $13(15.47 \%)$ \\
\hline
\end{tabular}

\section{DISCUSSION}

The internal carotid artery (ICA) represents the terminal branch of the common carotid artery that arises at the level of the superior margin of the thyroid cartilage. On the path to the underside of the brain, where it ends up giving its two terminal branches, it makes five curves. In relation to the part where it passes, the artery is divided into four parts: cervical, petrous, cavernous and cerebral part (Berkoviz \& Moxham; Bailey et al., 2006). Ziyal et al. (2005) described five segments of ICA: cervical, petrous, cavernous, clinoid and cisternal segment. In the petrous part of the temporal bone, the ICA is located in its bony canal, in which it firstly passes longitudinally across the anterior wall of the tympanic cavity, and then bends forward and medially below the auditory tube and trigeminal ganglion. The artery enters in the cranial cavity through the apex of the petrous part of the temporal bone (Somesh et al.).

Although the human skull is seemingly symmetrical, there are differences when considering the right and left sides. This asymmetry is a common finding, especially at the base of the skull (Russo \& Smith, 2011). In order to improve the different surgical approaches to the petrous part of the ICA, the details of the morphological and morphometric analysis of the EACC are of great importance.

In our study the average length of the EACC in the all measured specimens was $7.31 \pm 1.01 \mathrm{~mm}$ and $7.71 \pm 1.06$ $\mathrm{mm}$ on the right and left side. The average width of the EACC was $5.82 \pm 0.78 \mathrm{~mm}$ and $6.20 \pm 1.04 \mathrm{~mm}$ on the right and left side, respectively. We found similar values in the study by Tewary et al. and Berlis et al. In the study conducted by Watanabe et al. (2010), average width of the carotid canal in Japanese adults was $5.27 \pm 0.62 \mathrm{~mm}$, while much lesser values $(3.31 \pm 0.44 \mathrm{~mm})$ were observed in the patients with adultonset Moyamoya disease with ICA stenosis (Berlis et al.; Watanabe et al.; Tewary et al.). A comparison of our results with those of previous studies is shown in Table IV.

According to the results of our study there were no statistically significant differences of the length and width of the EACC between sides and sexes except for the parameter
AP which was statistically significant $(\mathrm{p}=0.017)$ between the right and left side on the female skulls. These results are in contrast with those of Aoun et al. (2013), and Shaikh \& Kulkarni (2014), who found statistically significant differences between male and female skulls in relation to the side. This, the different results of the studies may be related to population differences. Also, Aoun et al. did not find significant difference of the parameter AP in female skulls between right and left length values.

Between sexes and body sides there were no statistically significant differences in three additional parameters: CC-MS, CC-FM, CC-MP. These results are similar with study by Tewary et al.; Aoun $\mathrm{et}$ al. and Calgüner $\mathrm{et} \mathrm{al}$. (1997). In the study by Shaikh \& Kulkarni the comparison of the distance of EACC from Y axis (mid-sagittal line) in adult males and females was statistically significant (male had the higher values) on both left and right side which is in contrast with results of our study. This may be because they categorized the skulls into adolescent and adult groups.

According to the results of our study, the most common shape of the EACC was round ( 45 cases $-53.57 \%$ ), then oval ( 25 cases $-29.76 \%$ ), and the rarest was almond shaped (13 cases $-15.47 \%$ ). According to the literature data, similar results were found in a study by Somesh et al. and Tewary et al.. In a study by Naidoo et al., the most common shape of the EACC was oval $(49.4 \%)$, then round ( $28.4 \%)$, and the rarest was the tear shape $(22.2 \%)$. The one-way ANOVA test shown that there were no statistically significant differences between the shape of the EACC and its length $(\mathrm{F}(2,165)=0.129, \mathrm{p}=$ $0.87)$ or width $(\mathrm{F}(2,165)=1.847, \mathrm{p}=0.16)$.

It is interesting that literature research uses different terms and abbreviations for the external aperture of the carotid canal such as: external opening of the carotid canal (EOCC), external aperture of carotid canal (AECC) or (EACC), while some used just carotid canal (CC) (Aoun et al.; Shaikh \& Kulkarni; Somesh et al.; Tewary et al.; Naidoo et al.). To avoid nomenclature issues, the authors of this study invite future researchers to use a single nomenclature. 


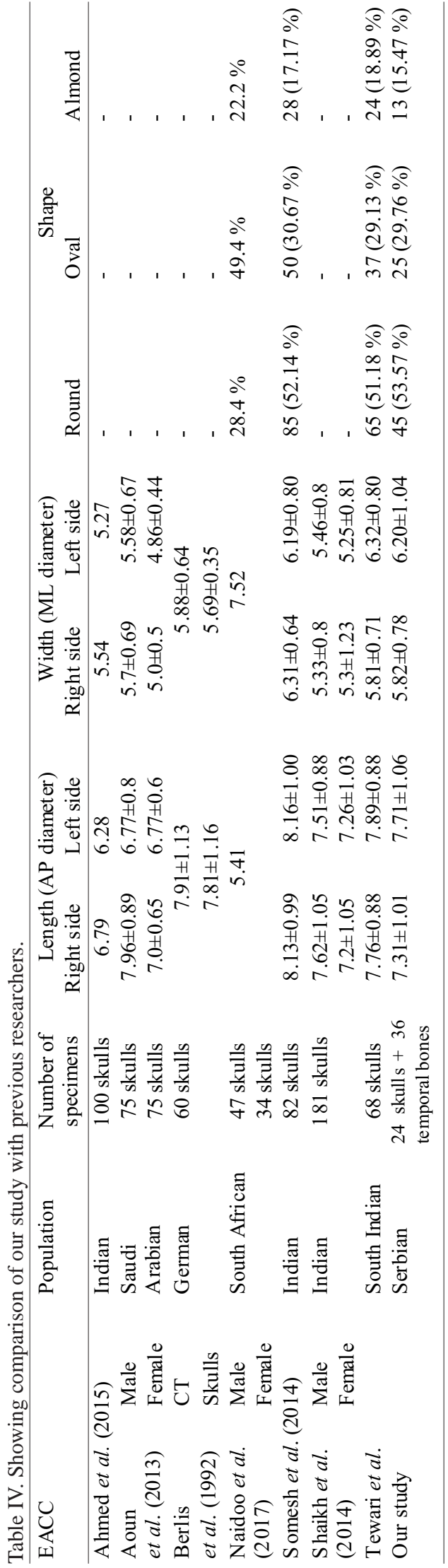

In conclusion, our study provides important information about size and position of the EACC, using various anatomical parameters on the basis of the skulls and the temporal bones of our adult population. These results may be of great benefit for neurosurgeons and neuroradiologists, to improve different surgical approaches to the petrous part of the internal carotid artery and prevent complications.

\section{ACKNOWLEDGEMENTS}

This work was supported by the Ministry of Education, Science and Technological Development of the Republic of Serbia (Grant OI175006).

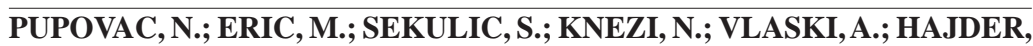
D. \& PETKOVIC, B. Análisis morfológico y morfométrico de la apertura externa del canal carotídeo en la población serbia. Int. J. Morphol., 38(4):1026-1031, 2020.

RESUMEN: El conducto carotídeo se encuentra en la parte petrosa del hueso temporal y da paso a la arteria carótida interna junto con el plexo nervioso venoso y simpático. La forma, ubicación y dimensiones del canal carotídeo son clínicamente muy importantes, especialmente en casos de cirugía de la base del cráneo. El objetivo de este estudio fue investigar los parámetros morfológicos y morfométricos de la apertura externa del canal carotídeo en la población serbia. El estudio incluyó 24 cráneos adultoss y 36 huesos temporales adultos secos. Se midieron los diámetros y distancias de la apertura externa desde varios puntos de referencia de la base del cráneo. También se observó la forma de la apertura del canal carotídeo externo. Los datos digitales se procesaron con Software ImageJ. La longitud promedio de la apertura en todos los especímenes investigados (cráneos y huesos temporales) en los lados derecho e izquierdo fue de 7,31 $\pm 1,01 \mathrm{~mm}$ y 7,71 $\pm 1,06 \mathrm{~mm}$, respectivamente. El ancho promedio de la apertura en el lado derecho fue de 5,82 $\pm 0,78 \mathrm{~mm}$ mientras que en el lado izquierdo fue de 6,20 $\pm 1,04 \mathrm{~mm}$. La frecuencia de las diferentes formas de la abertura externa fue la siguiente: redonda en $45(53,57 \%)$, ovalada en $25(29,76 \%)$, y la más rara fue la forma de almendra observada en $13(15,47 \%)$ casos. No hubo diferencias estadísticamente significativas en todos los parámetros medidos entre sexos y lados del cuerpo. La única estadística significativa se encontró en las mujeres entre el lado derecho e izquierdo en relación con la longitud (diámetro AP) de la apertura externa del conducto carotídeo. Los resultados de este estudio serán útiles para un mejor enfoque quirúrgico de los neurocirujanos en la parte petrosa de la arteria carótida interna, y advertir posibles complicaciones.

PALABRAS CLAVE: Canal carotídeo; Morfología; Morfometría; Cráneo; Hueso temporal.

\section{REFERENCES}

Ahmed, M. M.; Jeelani, M. \& Tarnum, A. Anthropometry: A comparative study of right and left sided foramen ovale, jugular foramen and carotid canal. Int. J. Sci. Stud., 35(5):88-94, 2015.

Aoun, A. M.; Nasr, A. Y. \& Aziz, A. Morphometric study of the carotid canal. Life Sci. J., 10(3):2559-62, 2013.

Bailey, B. J.; Johnson, J. T. \& Newlands, S. D. Head \& Neck Surgery-Otolaryngology. Philadelphia, Lippincott Williams \& Wilkins, 2006. 
Berkoviz, B. K. B. \& Moxham, B. J. A Text-book of Head and Neck Anatomy. London, Wolfe Medical Publications, 1988.

Berlis, A.; Putz, R. \& Schumacher, M. Direct and CT measurements of canals and foramina of the skull base. Br. J. Radiol., 65(776):653-61, 1992.

Calgüner, E.; Turgut, H. B.; Gözil, R.; Tunç, E.; Sevim, A. \& Keskil, S. Measurements of the carotid canal in skulls from Anatolia. Acta. Anat. (Basel), 158(2):130-2, 1997.

Chimmalgi, M.; Kulkarni, Y. \& Sant, S. M. Sexing of skull by new metrical parameters in Western India. J. Anat. Soc. India, 56(1):28-32, 2007.

Cicekcibasi, A. E.; Murshed, K. A.; Ziylan, T.; Seker, M. \& Tuncer, I. A morphometric evaluation of some important bony landmarks on the skull base related to sexes. Turk. J. Med. Sci., 34:37-42, 2004.

Naidoo, N.; Lazarus, L.; Ajayi, N. O. \& Satyapal, K. S. An anatomical investigation of the carotid canal. Folia Morphol. (Warsz.), 76(2):28994, 2017.

Resnick, D. K.; Subach, B. R. \& Marion, D. W. The significance of carotid canal involvement in basilar cranial fracture. Neurosurgery, 40(6):117781, 1997.

Russo, P. P. \& Smith, R. L. Asymmetry of human skull base during growth. Int. J. Morphol., 29(3):1028-32, 2011.

Shaikh, V. G. \& Kulkarni, P. R. A Study of morphology, morphometry, symmetry and development of external opening of carotid canal with comparison in male, female and foetus. Int. J. Anat. Res., 2(4):797805, 2014.

Somesh, M. S.; Sridevi, H. B.; Murlimanju, B. V. \& Pai, R. S. Morphological and morphometric study of carotid canal in indian population. Int. J. Biomed. Res., 5(7):455-60, 2014.

Standring, S. Gray's Anatomy. $41^{\text {st }}$ ed. Edinburgh, Elsevier Churchill Livingstone, 2016.

Stevenson, J. C.; Mahoney, E. R.; Walker, P. L. \& Everson, P. M. Technical note: prediction of sex based on five skull traits using decision analysis (CHAID). Am. J. Phys. Anthropol., 139(3):434-41, 2009.

Tewari, S.; Gupta, C.; Palimar, V. \& Aithal, S. Morphometric analysis of the external aperture of the carotid canal in skulls of South Indian origin. J. Morphol. Sci., 35(4):261-5, 2018.

Watanabe, A.; Omata, T.; Koizumi, H.; Nakano, S.; Takeuchi, N. \& Kinouchi, H. Bony carotid canal hypoplasia in patients with moyamoya disease. J. Neurosurg. Pediatr., 5(6):591-4, 2010.

York, G.; Barboriak, D.; Petrella, J.; DeLong, D. \& Provenzale, J. M. Association of internal carotid artery injury with carotid canal fractures in patients with head trauma. AJR Am. J. Roentgenol., 184(5):16728, 2005.

Ziyal, I. M.; Ozgen, T.; Sekhar, L. N.; Ozcan, O. E. \& Cekirge, S. Proposed classification of segments of the internal carotid artery: anatomical study with angiographical interpretation. Neurol. Med. Chir. (Tokyo), 45(4):184-90, 2005.

\author{
Corresponding author: \\ Nikolina Pupovac, MD, PhD student \\ Department of Anatomy \\ Faculty of Medicine \\ University of Novi Sad \\ Hajduk Veljkova 3 \\ 21000 Novi Sad \\ SERBIA
}

E-mail: nikolinapupovac@yahoo.com

Received: 22-11-2019

Accepted: 13-02-2020 